\title{
Screening of mutations in NOL3 in a myoclonic syndromes series
}

\author{
A. Macerollo • N. E. Mencacci - R. Erro • \\ C. Cordivari $\cdot$ M. J. Edwards $\cdot$ N. W. Wood $\cdot$ \\ Kailash P. Bhatia
}

Received: 15 May 2014/Revised: 4 August 2014/ Accepted: 5 August 2014/Published online: 20 August 2014

(C) The Author(s) 2014. This article is published with open access at Springerlink.com

Dear Sirs,

Recently, Russel and colleagues [1] performed a detailed genetic analysis of a four-generation family with a phenotype characterized by autosomal dominant, adult onset, cortical myoclonus without associated seizures. The authors proposed the term familial cortical myoclonus (FCM).

They demonstrated linkage to chromosome 16q21-22.1 and identified the E21Q missense change in NOL3 (nucleolar protein 3 ) as the only segregating novel variant [1].

The NOL3 gene encodes a 208 amino acid protein that is expressed in heart, skeletal muscle, and brain. The amino acid A80, involved by the mutation we identified, resides in the N-terminal CARD, a motif that mediates protein-protein binding via electrostatic interactions. One possibility is that the A80T variant, similarly to what was hypothesized for the E21Q described by Russel and colleagues, may alter the electrostatic surface potential of the NOL3 CARD domain and change its binding properties for interaction with protein partners. Given the absence of an excitability phenotype in NOL3 knock-out mice and the presence of

A. Macerollo and N. E. Mencacci contributed equally to this work.

A. Macerollo $(\square) \cdot$ R. Erro $\cdot$ C. Cordivari $\cdot$

M. J. Edwards · N. W. Wood - K. P. Bhatia

Sobell Department of Motor Neuroscience and Movement

Disorders, Institute of Neurology, University College London,

London, UK

e-mail: antonella.mac@hotmail.it

K. P. Bhatia

e-mail: k.bhatia@ucl.ac.uk

N. E. Mencacci · N. W. Wood

Department of Molecular Neuroscience, Institute of Neurology,

University College London, London, UK heterozygous loss-of-function variants in neurologically normal human control subject, it seems plausible that pathogenic NOL3 mutations may cause neuronal hyperexcitability through a gain-of-function mechanism $[2,3]$.

To investigate the contribution of the mutations in NOL3 gene in myoclonic patients of British origin, we analyzed the complete coding sequence of NOL3 in a cohort of 107 subjects (features summarized in Table 1).

Cases were selected where they were affected with cortical myoclonus or with either isolated subcortical myoclonus (previously known as essential myoclonus) or a combination of myoclonus and dystonia. We excluded patients who were positive for mutations in the $S G C E$, the most common genetic cause of myoclonus-dystonia [4]. Secondary forms of myoclonus had been excluded with the appropriate investigations.

We included three unrelated cases of autosomal dominant FCM with onset in the beginning of the third decade. In all patients cortical myoclonus was not associated with epilepsy. These patients underwent somatosensory evoked potentials (SSEPs) studies, which showed clear giant evoked potentials [5].

Furthermore, we included seven cases of sporadic cortical myoclonus without seizures. Myoclonus was triggered by action or inadvertent somatosensory stimuli. Video EEG-EMG recording with back-averaging analysis was performed in all patients, confirming the cortical origin of the myoclonus. Three of these seven patients also underwent SSEPs studies, which disclosed enlarged responses. Secondly, to explore the potential role of NOL3 in myoclonus-related phenotype, we studied 97 patients affected by either familiar or sporadic undiagnosed myoclonus-dystonia-like syndrome. Our cohort included 11 familial cases with autosomal dominant pattern of inheritance and 86 sporadic cases. 
Table 1 Demographics and clinical diagnoses of all patients

\begin{tabular}{llll}
\hline $\begin{array}{l}\text { Type of } \\
\text { myoclonus } \\
\text { syndrome }\end{array}$ & $\begin{array}{l}\text { Number of patients (sex } \\
\text { ratio: male/female) }\end{array}$ & Age $^{\mathrm{a}}$ & $\begin{array}{l}\text { Age at } \\
\text { onset }^{\mathrm{a}}\end{array}$ \\
\hline $\begin{array}{l}\text { Myoclonus-dystonia-like } \\
\text { - Familial cases }\end{array}$ & $11(6 / 5)$ & & \\
- Sporadic case & $86(37 / 49)$ & $49 \pm 15$ & $28 \pm 18$ \\
Cortical myoclonus & & $50 \pm 17$ & $27 \pm 15$ \\
- Familial cases & $3(1 / 2)$ & $46 \pm 8$ & $24 \pm 6$ \\
- Sporadic case & $7(2 / 5)$ & $59 \pm 9$ & $22 \pm 4$ \\
Total & $107(46 / 61)$ & $50 \pm 16$ & $27 \pm 15$ \\
\hline
\end{tabular}

${ }^{\text {a }}$ Mean age in year \pm standard deviation (SD)

In the 107 patients screened, we identified only one novel single nucleotide mutation in NOL3 (c.238G $>\mathrm{A}$; p.A80T) in one subject. This variant was absent in the 1000 genome project (http://www.1000genomes.org/) and Exome Variant Server (http://evs.gs.washington.edu/EVS/) databases. It is predicted to be damaging by Polyphen-2 (HumVar-trained http://genetics.bwh.harvard.edu/pph2/) and Mutation Taster (http://www.mutationtaster.org/) but tolerated by SIFT (http://sift.jcvi.org/). The amino acid residue involved by the missense change is conserved through species.

The mutation was identified in a male patient who exhibited myoclonic jerks affecting the face and both arms (right $>$ left) that started in the fourth decade. The abnormal movements often developed into fast rhythmic clusters of jerks, but they did not show stimulus sensitivity. There was no family history of such conditions. The EEG did not show cortical correlates of myoclonic jerks. Furthermore, he was affected by epilepsy characterized by generalized seizures since age 15 for which he was on Sodium Valporate.

No other possibly pathogenic variants were identified.

The missense mutation p.E21Q, which was found to segregate in the pedigree described by Russel et al. [1], was not identified in our cohort. Functional work proving the functional effect whereby the identified NOL3 change could lead to membrane hyperexcitability and cortical myoclonus is still lacking. This leaves open the possibility that the detected variant could be a private mutation or a very rare benign variant linked to the actual disease mutation but not itself pathogenic [6].
However, we have identified a new variant, p.A80T, in one patient of our cohort. Notably, the phenotype of our NOL3 mutation carrier is different from what has been previously described. Indeed, our patient had subcortical myoclonus, seizures and no family history for such disorders. Unfortunately other family members were not available for clinical or genetic analysis, therefore the pathogenic role of the detected variant remains uncertain. Further reports of large series of patients suffering from either familial or sporadic cortical myoclonus or related phenotypes looking at NOL3 variants are needed as well as functional studies on the gene function.

\section{Conflicts of interest None.}

Ethical standard This study has been approved by the Ethics Committee of the institute of Neurology, University College of London. Informed Consent was obtained by each patient included in the study.

Open Access This article is distributed under the terms of the Creative Commons Attribution License which permits any use, distribution, and reproduction in any medium, provided the original author(s) and the source are credited.

\section{References}

1. Russell JF, Steckley JL, Coppola G, Hahn AF, Howard MA, Kornberg Z, Huang A, Mirsattari SM, Merriman B, Klein E, Choi M, Lee HY, Kirk A, Nelson-Williams C, Gibson G, Baraban SC, Lifton RP, Geschwind DH, Fu YH, Ptáček LJ (2012) Familial cortical myoclonus with a mutation in NOL3. Ann Neurol $72: 175-183$

2. Engidawork E, Gulesserian T, Yoo BC et al (2001) Alteration of caspases and apoptosis-related proteins in brains of patients with Alzheimer's disease. Biochem Biophys Res Commun 281:84-93

3. Shelke RR, Leeuwenburgh C (2003) Lifelong caloric restriction increases expression of apoptosis repressor with a caspase recruitment domain (ARC) in the brain. FASEB J 17:494-496

4. Valente EM, Edwards MJ, Mir P, Di Giorgio A, Salvi S, Davis M, Russo N, Bozi M, Kim HT, Pennisi G, Quinn N, Dallapiccola B, Bhatia KP (2005) The epsilon-sarcoglycan gene in myoclonic syndromes. Neurology 64:737-739

5. Kojovic M, Cordivari C, Bhatia K (2011) Myoclonic disorders: a practical approach for diagnosis and treatment. Ther Adv Neurol Disord 4:47-62

6. Haines JL (2013) The importance of rare DNA variation in neurologic disease: cautionary tale. Neurology 80:974-975 